\title{
APRENDIZAGEM NA/DA ETNOGRAFIA: REFLEXÕES CONCEITUAL-METODOLÓGICAS A PARTIR DE DOIS CASOS BEM BRASILEIROS
}

\author{
Ana Maria Rabelo Gomes (UFMG)* \\ https://orcid.org/0000-0003-0156-2112 \\ Eliene Lopes Faria (UFMG)** \\ https://orcid.org/0000-0001-7463-4135 \\ Renata Silva Bergo (IEAR/UFF)*** \\ https://orcid.org/0000-0002-6218-0911
}

\section{RESUMO}

0 artigo aborda as relações entre etnografia e aprendizagem, tema assumido como interface estratégica entre os campos da Educação e da Antropologia. São explorados dois casos - o futebol e as religiões de matriz africana - cujas práticas culturais são difusas e constitutivas da experiência de diferentes segmentos sociais no Brasil, para abordar os processos de aprendizagem nos dois contextos, inclusive das próprias etnógrafas que deles participaram. Assumiu-se a necessária condição situada destes processos, para que fossem apreendidos na riqueza que nos interessava explicitar, ou seja, na forma como essas práticas acontecem e são (re)produzidas especificamente no Brasil. A partir da proposta de aprendizagem situada desenvolvida por Jean Lave, revelam-se algumas das especificidades da prática da etnografia e dos modos de aprender em cada caso, para refletir e buscar anunciar os novos cenários em que estamos construindo hoje nossas práticas e pesquisas com diferentes coletivos.

Palavras-chave: Aprendizagem situada. Etnografia. Umbanda. Futebol.

\section{ABSTRACT}

\section{LEARNING AND ETHNOGRAPHY: CONCEPTUAL-METHODOLOGICAL ISSUES FROM TWO VERY BRAZILIAN CASES}

The article addresses the relationship between ethnography and learning, a

* Doutora em Educação pela Università di Bologna (Italia). Pos-Doutora em Antropologia Social pelo Programa de PósGraduação em Antropologia Social do Museu Nacional/Universidade Federal do Rio de Janeiro (PPGAS/Museu Nacional/ UFRJ). Professora Titular no Departamento de Ciências Aplicadas à Educação da Faculdade de Educação da Universidade Federal de Minas Gerais (UFMG). E-mail: anagomes@ufmg.br

** Doutora em Educação pela Universidade Federal de Minas Gerais (UFMG). Professora Adjunta do Mestrado Profissional da Faculdade de Educação da Universidade Federal de Minas Gerais (UFMG). E-mail: elienelopesfaria@gmail.com

*** Doutora em Educação pela Universidade Federal de Minas Gerais (UFMG). Professora Adjunta e Coordenadora do Curso de Pedagogia do Instituto de Educação de Angra dos Reis, da Universidade Federal Fluminense (IEAR/UFF). E-mail: renatabergo@ id.uff.br 
theme assumed as a strategic interface between the fields of education and anthropology. Two cases are explored - soccer and Afro-Brazilian religions whose cultural practices are diffuse and constitutive of the experience of different social segments in Brazil, to address the learning processes in both contexts, including the ethnographers who participated in them. The necessary situated condition of these processes is assumed, so that they could be apprehended in the richness that we were interested in making explicit, that is, in the way these practices happen and are (re) produced specifically in Brazil. From the situated learning proposal developed by Jean Lave, we unveil some specificities of the practice of ethnography and the ways of learning in each case, to reflect and to announce the new scenarios in which we are building our practices and researches with different collectives today.

Keywords: Situated learning. Ethnography. Umbanda. Soccer.

\section{RESUMEN}

\section{APRENDIZAJE EN / DE ETNOGRAFÍA: REFLEXIONES CONCEPTUAL- METODOLÓGICAS DESDE DOS CASOS MUY BRASILEÑOS}

El artículo aborda la relación entre etnografía y aprendizaje, tema asumido como interface estratégico entre los campos de la educación y la antropología. Se exploran dos casos, el fútbol y las religiones afrobrasileñas, cuyas prácticas culturales son difusas y constitutivas de la experiencia de diferentes segmentos sociales en Brasil, para abordar los procesos de aprendizaje en ambos contextos, incluidos los etnógrafos que participaron en ellos. Se supuso la condición situada de estos procesos, de modo que pudieran ser aprehendidos en la riqueza que estábamos interesados en hacer explícito en la forma en que estas prácticas suceden y se (re) producen. A partir de la propuesta de aprendizaje situado desarrollada por J. Lave, revelamos algunas especificidades de la práctica de la etnografía y las formas de aprendizaje en cada caso, para reflexionar y anunciar los nuevos escenarios en los que actualmente estamos construyendo nuestras prácticas e investigaciones con diferentes colectivos.

Palabras clave: Aprendizaje situado. Etnografía. Umbanda. Fútbol.

\section{Introdução}

As pesquisas aqui apresentadas, e as reflexões que com elas trazemos, são fruto de um percurso que vem se desenvolvendo desde 2011, quando nos voltamos para o tema da aprendizagem enquanto tema de interface em diversos sentidos. Como tema que poderia fazer dialogar os campos da Educação e da Antropologia, assumindo que a fórmula inicialmente genérica da "aprendizagem da cultura" (GOMES, 2014) poderia ser uma provocação para a desnaturalização de processos de aprendizagem que nos são muito próximos e familiares, sem por isso serem conhecidos (DAMATTA, 1978). Nesse sentido, os dois casos aqui convocados ao diálogo trazem experiências de dois âmbitos considerados reconhecidamente brasileiros, cujas práticas culturais são difusas e expressivamente constitutivas da experiência de diferentes segmentos sociais em nosso país: as muitas dimensões do que é a prática do futebol no Brasil; e as práticas das diversas religiões de matriz africana. ${ }^{1}$

1 Embora não seja possível fazer aqui um maior desenvolvimento dessa afirmação, as interfaces que 
A etnografia foi a abordagem conceitualmetodológica escolhida para buscar conhecer e explorar o que viriam a ser os processos de aprendizagem das práticas do futebol e das práticas das religiões de matriz africana por muitas e diversas razões, cabendo ressaltar aqui o pouco conhecimento que se tem sobre tais processos em nosso país; e ainda ressaltar e assumir a necessária condição situada desses processos, para que fossem apreendidos na riqueza que nos interessava explicitar, ou seja, na forma como essas práticas acontecem e são (re)produzidas especificamente no Brasil (GOMES et al., 2012). ${ }^{2}$ Tal abordagem também nos permitiu ensaiar um diálogo entre campos temáticos que frequentemente não se entrelaçam, buscando gerar uma aproximação entre temas pesquisados, mas também entre os pesquisadores e entre os próprios praticantes. Trata-se de uma tentativa de abrir um cenário mais amplo de encontros e convergências na universidade, para além de um diálogo formal supostamente promovido pelas teorias, essas, sim, consideradas adequadas para realizar o trânsito entre diferentes contextos - temáticos, acadêmicos e de práticas. Interessava-nos buscar perspectivas para promover uma aproximação entre os sujeitos mesmos das experiências, os diferentes praticantes. E esta perspectiva tem sido mais um elemento balizador no crivo que as pesquisas de campo sempre projetam sobre as diferentes teorias.

Falar em práticas situadas e aprendizagem necessariamente nos remete à proposta desenvolvida por Jean Lave (LAVE, 2011, 2019; LAVE; WENGER, 1991). É a partir do quadro

se revelaram mais profícuas foram as que ocorreram entre campos específicos como Antropologia da Técnica e da Tecnologia, a atenção à dimensão material das práticas culturais (a cultura material); Antropologia da Criança e da Infância; Antropologia do Corpo; Antropologia das Religiões, em específico as pesquisas sobre religiões de matriz africana. Temas abrangentes têm sido mobilizados, como a concepção e formação da pessoa em diferentes configurações sociais e a noção de socialidade (STRATHERN; TOREN, 1996), além dos que serão abordados no artigo.

2 As pesquisas conduzidas e em curso envolvem outras temáticas que não serão aqui referidas. acima descrito que retomamos alguns pontos chave da revisão que Lave (2019) faz do livro Situated Learning, para com ela refletir e buscar anunciar os novos cenários em que estamos construindo hoje nossas práticas e pesquisas etnográficas, nos dirigindo a diferentes coletivos.

Duas são as ideias principais, quer se trate de uma abordagem para as pesquisas e projetos em curso, quer se trate de refletir sobre nossa própria prática: "Descentrando a pesquisa sobre aprendizagem" e "Somos todos aprendizes de nossa própria prática em mudança" (LAVE, 2019, p. 133-134).

\section{Descentrando a pesquisa sobre aprendizagem}

Afirma Lave (2019) que, na releitura do livro Situated Learning, à luz das interações e reações ocorridas após mais de 25 anos de sua publicação, o mais importante "movimento" teórico do livro não seria a proposição, nele central, do caráter situado da prática e, de consequência, da aprendizagem; mas sua insistência em que isso implica e exige uma investigação descentralizada da aprendizagem. "Afinal, a aprendizagem é sempre apenas parte da mudança da prática, em um mundo em mudança" (LAVE, 2019, p. 134).

Essa autora então resume em uma sequência de pontos esse argumento, para finalizar com a sua referência original:

A aprendizagem é apenas uma parte de um continuum da prática. $\mathrm{O}$ aprendizado situado como participação periférica legitimada torna a participação inseparável dos participantes na prática e as práticas parcialmente incorporadas na mudança dos participantes. As práticas das quais os participantes fazem parte são condições necessárias para a aprendizagem. 0 objeto de análise, portanto, precisa ser uma paisagem texturizada de participação. Estudos sobre a aprendizagem como participação periférica legitimada em comunidades de prática começam aí. Um enfoque coerente para tais observações emerge do descentramento do estudo da 
aprendizagem - 'mudar a noção de um aprendiz individual para o conceito de participação periférica legitimada em comunidades de prática é, precisamente, descentralizar a análise da aprendizagem' (Lave e Wenger, 1991, p. 94). (LAVE, 2019, p. 135, grifo nosso).

Ao se referir à pesquisa realizada entre os alfaiates na Libéria (LAVE, 2011), ela chama atenção para o fato que foi uma tentativa de abordar o tema da aprendizagem sem as demarcações próprias do contexto escolar que reiteradamente influenciam as pesquisas sobre aprendizagem, ainda que de forma muitas das vezes implícitas. A começar pela crítica às definições feitas pela negação - o formal e o não-formal; o escolar e o não-escolar - que sempre servem mais a obliterar do que a revelar aspectos importantes do que está sendo observado.

No sentido então de indagar sobre as "condições de possibilidade da aprendizagem", Lave (2019) afirma que o capítulo 4 de Situated Learning focaliza essa exploração das possíveis direções da observação, para que a aprendizagem seja assumida como parte das práticas em curso. Ela insiste em buscar apreender o que é visto como recurso que torna possível, ou que viabiliza a aprendizagem, do ponto de vista dos aprendizes.

A partir da ideia de "estruturar recursos para a aprendizagem na prática”, buscava-se entender como, "dependendo da organização do acesso, a condição de periferia legitimada pode promover ou impedir a participação legitimada" (LAVE; WENGER, 1991, p. 103, grifo do autor). A ideia do acesso às práticas foi desdobrada de formas muito variadas em diferentes pesquisas (GOMES et al., 2012), e será aqui importante. Assim como as negociações que se dão em campo e legitimam - ou não - a participação das etnógrafas e tem incidência fundamental na condução das práticas da própria etnografia.

Afirma ainda Lave (2019) que, ao mesmo tempo em que toma absoluta distância do termo cognição, a proposta é que o termo participação seja lido pelo menos em dois sentidos: para referir às pessoas participando nas práticas; mas também às práticas que são constituídas pela participação das pessoas ambos como um único e imbricado (e controverso) processo.

Passamos então ao cenário mais recente que nos desafia, e que, partindo dessas provocações, assume que fazer etnografia é um processo de contínua aprendizagem.

\section{"Somos todos aprendizes de nossa própria prática em mudança": aprendendo com a etnografia}

Com essa afirmação, vamos então introduzir os dois casos, assumindo a ideia de aprendizagem como mudança na forma de participação na prática. Vamos ver como essa orientação pode então guiar uma releitura sobre as atividades de campo quanto às práticas que estavam sendo investigadas; e, ao mesmo tempo, guiou a própria aprendizagem das pesquisadoras como etnógrafas em campo, que foram aprendendo a se mover na medida mesma em que aprendiam sobre o próprio campo/tema da pesquisa.

Fazer pesquisa é prática situada - e aprender a fazer pesquisa significa mudar nosso modo de participar. Essa premissa pode valer para todos os envolvidos, nesse momento em que as fronteiras entre pesquisador e pesquisado se mesclam, e tem se produzido vários "atravessamentos", ou deslocamentos. ${ }^{3}$

3 Referimo-nos aqui à experiência na Faculdade de Educação da Universidade Federal de Minas Gerais (FaE/UFMG) de mais de 20 anos com a formação de professores indígenas, além do programa de vagas suplementares nos demais cursos; ao sistema de reserva de vagas na graduação e agora também na pós-graduação para negros e indígenas. Ou seja, hoje temos uma presença crescente e institucionalizada de pessoas de diferentes proveniências, muitas dos quais habituadas a receber pesquisadores em suas comunidades ao longo desses 20 anos, e agora passando a transitar elas próprias como pesquisadores e pesquisadoras nos espaços da universidade. 


\section{Etnografia em um terreiro de umbanda}

0 que um terreiro de umbanda tem a dizer sobre aprendizagem? Para responder a essa pergunta serão apresentados nesse texto os processos de construção e reconstrução dos contornos da pesquisa etnográfica realizada por Bergo (2011) quando da produção de sua tese de doutorado intitulada Quando o santo chama: o terreiro de umbanda como contexto de aprendizagem na prática. 0 objetivo é apresentar como o caminho teórico-metodológico percorrido pela pesquisadora foi sendo definido pela sua própria experiência de campo. Pretendemos mostrar que a realização da referida pesquisa tornou evidente como as contingências e constrangimentos próprios da investigação determinam o que deve ser observado e a quem é preciso se dirigir no universo estudado, intervindo diretamente na definição (ou redefinição) das relações que compõem a pesquisa. ${ }^{4}$

Apesar do foco de interesse ter permanecido sempre o mesmo, o percurso de produção da etnografia foi marcado por muitas e significativas mudanças, inclusive tendo começado em um contexto absolutamente distante do universo religioso, quanto mais umbandista.

Interessada em compreender processos de aprendizagem na prática (LAVE; WENGER, 1991), a pesquisadora realizou inicialmente uma investigação exploratória em que buscou conhecer o cotidiano de projetos socioeducativos de diferentes naturezas e propósitos (governamentais, ONGs, religiosas, comunitárias e associativas). Intencionava localizar experiências educativas/formativas que apresentassem modos peculiares de "socialização" e "circulação de saberes". Dentre as

4 Depois da realização da pesquisa, surgiram interessantes trabalhos que focalizaram a aprendizagem no candomblé (CAPUTO, 2012; OLIVEIRA; ALMIRANTE, 2017; RABELO, 2015; RABELO; SANTOS, 2011), que têm pontos de convergência e especificidades que não cabem ser aqui tratados, uma vez que estamos privilegiando o percurso inicial da pesquisa. mais variadas atividades que pôde acompanhar, as que se destacaram por apresentarem uma organização bastante curiosa e que mais se diferenciava da organização escolar foram oficinas de percussão.

De maneira geral, o verbo aprender - sobretudo quando nos referimos à infância - parece estar inevitavelmente associado a certas estruturas e condições, tais como: escola, professor, aluno, sala de aula, materiais didáticos; além da noção de que se trata de um processo individual e que ocorre na mente das pessoas. Essas associações diretas, tão fortemente presentes no nosso cotidiano, chegam a impedir que pensemos em outros modos de compreender o que é educação em sentidos mais amplos.

Não obstante, um olhar atento, voltado para distintos contextos sociais e culturais, pode abrir um caminho extremante rico a ser explorado na busca por uma ampliação do conhecimento sobre processos educativos, especialmente sobre modos de aprender. Como as oficinas de percussão se mostraram terrenos férteis para abordar essas questões, uma delas em específico - a que apresentava características mais instigantes - foi escolhida para a realização do trabalho de campo.

Nessa fase da pesquisa, Bergo (2011) considerou adotar uma postura investigativa semelhante à utilizada por Wacquant (2002) em seu estudo realizado em um ginásio de boxe em uma comunidade afro-americana de baixa renda na cidade de Chicago. Sendo assim, ao se tornar ele próprio um aprendiz de boxeador em seu campo empírico (uma academia de pugilistas), ele era ao mesmo tempo o observador, o objeto e o sujeito da observação. Wacquant (2002, p. 60) lançou mão dessa metodologia por considerar o boxe como uma prática por excelência e que, por isso, exige que "mergulhemos nele como pessoa, que nele se faça a aprendizagem e que se viva as principais etapas desde o interior".

Ao se posicionar como uma "aprendiz de percussão", Bergo (2011) pretendia então explorar aspectos inerentes ao processo de 
aprender uma determinada prática ou técnica e também aspectos "didáticos-metodológicos" presentes na oficina. Não obstante, foram as próprias contingências do campo empírico que apresentaram um novo universo de possibilidades investigativas.

Me dispus a ser uma aprendiz-observadora das oficinas de tambor [...], no período de um ano completo. Além do caderno de campo, utilizei como instrumento de registro a gravação, ${ }^{5} \mathrm{em}$ um aparelho de MP3, de tudo o que se passava nas oficinas. Contudo, apesar da experiência ter sido riquíssima, ao final de todo esse período e com um enorme volume de material produzido, ainda não havia conseguido definir o foco da análise a ser desenvolvida. (BERGO, 2011, p. 19, grifo do autor).

\section{Redefinição da pesquisa}

Visando uma imersão cada vez maior no campo, a pesquisadora buscou compartilhar com os outros participantes não só as atividades da oficina, mas também diferentes momentos de descontração e conversas informais. Em uma destas muitas conversas, o oficineiro contou como suas primeiras incursões no mundo da música estiveram profundamente atreladas a sua história familiar e religiosa.

PESQUISADORA: E seu pai tocava muito?

OFICINEIRO: Ele arriscava bem. Eu me lembro dele tocando coisas harmônicas, tipo sanfona, que é até difícil de tocar, eu não sei nada. Mas eu me lembro bem na minha mente porque... Essa coisa dele cantarolar umas coisas antigas, compor, ele tinha algumas composições.

PESQUISADORA: Ah, é? Ele tocava o que? Sanfona e o que mais?

OFICINEIRO: Que eu me lembre é essa coisa de percussão, atabaque, por causa do próprio espiritismo. Por ser um ogã, ele ajudou a construir as coisas na minha família-de-santo. Que eu sou ogã também, né?

PESQUISADORA: Você é o que? Ogã? Que é isso?

5 Procedimento adotado mediante expressa autorização tanto do oficineiro como dos participantes. Terminada essa fase da pesquisa, contava-se com aproximadamente 150 horas de gravação.
OFICINEIRO: [Soltou uma grande gargalhada]. ${ }^{6}$

Diante do meu espanto e ignorância, permeados por um enorme interesse em compreender melhor a influência do 'espiritismo"7 em sua formação musical, os temas de nossos bate-papos passaram a girar quase exclusivamente em torno dessa temática. Foi a partir daí que o percussionista e compositor começou a ceder lugar para que o ogã se manifestasse. Sem que eu pudesse prever, o querido 'mestre' de percussão foi se tornando cada vez mais um imprescindível guia a conduzir a pesquisa por caminhos nunca antes sequer imaginados. (BERGO, 2011, p. 21, grifo nosso).

A partir daquele momento, uma nova etapa do estudo teve início, visando localizar mais precisamente na história de vida desse rapaz as circunstâncias que possibilitaram o seu acesso ao universo musical e artístico e, mais especificamente, como se deu seu aprendizado da percussão. Entretanto, no processo de adensamento do trabalho de campo, houve um convite para que a pesquisadora conhecesse seus familiares e sua residência, onde funcionava um terreiro de umbanda comandado por seu irmão. Esses episódios acabaram se configurando como passos decisivos para a redefinição dos contornos da pesquisa.

Conforme nos referimos anteriormente, o propósito de fundo da pesquisa sempre foi o interesse em problematizar a questão da aprendizagem para além dos contextos de estruturação pedagógica, buscando conhecer e compreender práticas sociais em que o aprender acontece de modo peculiar, como parte inerente às práticas nas quais os sujeitos se encontram envolvidos. Com essas questões em mente, Bergo (2011) iniciou as incursões ao terreiro de umbanda, que a princípio se de-

6 Entrevista realizada em 25 de agosto de 2008.

7 Nos primeiros contatos com os membros da família do oficineiro, todos se diziam "espíritas", porém não tardaram a especificar a natureza umbandista desse espiritismo. Autodeclarar-se espírita é um recurso comumente utilizado por adeptos de religiões mediúnicas, sobretudo dos cultos de matriz africana. Isso pode ser compreendido, pelo menos, de duas formas: o espiritismo goza de melhor prestígio social do que a religiões de matriz africana; e o fato da origem da umbanda ter sido fortemente influenciada por princípios da doutrina kardecista. 
ram de maneira casual, mas que rapidamente tomaram um caráter etnográfico.

Não obstante, é preciso dizer que o fascinante e misterioso novo contexto de pesquisa que começava a se configurar trouxe inquietações de natureza pessoal para a pesquisadora e também alguns conflitos de ordem teórico-metodológica. No que se refere às questões pessoais, toda a carga de uma inserção desde sempre em uma cultura cristã conservadora mostrou a sua força. A falta de conhecimento não só a respeito da umbanda, mas também acerca das religiões de matriz africana de maneira geral, era reforçada por uma série de mitos e leituras distorcidas produzidas por uma educação que se deu exclusivamente dentro dos dogmas e preceitos da Igreja Católica.

Entretanto, foi interessante observar que justamente esse desconhecimento e o fato de ser uma pessoa "de fora" da religião possibilitaram uma entrada em campo muito positiva e acolhedora, pois as perguntas e a presença frequente da pesquisadora foram vistas como provas de um real e legítimo interesse. Mais do que causar estranheza, os membros e frequentadores do terreiro encaram a possibilidade de conviver com alguém empenhado em estudar (e não utilizar) a umbanda como uma curiosa e rica oportunidade de troca de vivências e saberes.

Já os conflitos e dúvidas de ordem teórico-metodológica permaneceram ao longo de toda a realização da etnografia. Como continuar conduzindo o trabalho de campo e, posteriormente, a produção de uma análise e uma escrita que dessem conta de uma prática cultural absolutamente diversa e dinâmica, que se fundamenta em elementos impossíveis de se definir com precisão e que fogem completamente a uma análise objetiva, como fé, dom, mediunidade, possessão e magia? Um universo no qual o mais essencial aprendese além e aquém da linguagem e até mesmo da consciência; uma comunidade de prática feita de homens e mulheres de carne e osso, mas também por deuses, santos e espíritos de "luz" e de "trevas" envolvidos em uma intensa e cotidiana relação?

A teoria da aprendizagem situada proposta por Lave e Wenger (1991), que já vinha orientando o trabalho desde o início, trouxe grande contribuição para pensar a respeito de diferentes aspectos que nos interessavam da prática umbandista. Partindo do entendimento de que aprendizagem é inerente a toda prática social, esses autores sugerem uma mudança de foco bastante inquietante e inspiradora: não mais centrar a atenção no indivíduo como aprendiz, e sim pensar a aprendizagem constituída pelas relações que ocorrem como participação nas práticas sociais.

Num primeiro momento, a observação participante aconteceu exclusivamente em situações mais comuns e mais conhecidas dos terreiros (festas, sessões, cerimônias, "puxadas", "trabalhos"). Entretanto, rapidamente percebeu-se que, para compreender a prática umbandista, não bastava frequentar as festas públicas ou as cerimônias grandiosas; seria preciso acompanhar o dia a dia do grupo de fiéis. Ficou claro que os fundamentos da umbanda estão de tal modo intrincados no curso dos acontecimentos cotidianos que são efetivamente parte do mundo ordinário dos seus praticantes. Bergo (2011) foi conduzida, então, a uma aproximação cada vez mais efetiva de tal contexto, visando entender como os sujeitos lidavam cotidianamente com as questões relativas à religião que professam.

Um dos grandes desafios desse trabalho foi buscar escapar aos padrões preestabelecidos no imaginário coletivo que, de modo geral, centralizam a atenção nos aspectos percebidos como exóticos das religiões de matriz africana. Paulatinamente, tornou-se evidente que a preparação dos rituais e cerimônias revelavam mais sobre a complexidade da prática religiosa do que o próprio evento em si. Afinal, é na vida cotidiana, e não tanto durante os rituais, que se manifestam as graças que as entidades espirituais concedem aos "seus filhos", e também as punições e cobranças que fazem a eles. Apren- 
dizagem e vida cotidiana se apresentavam de forma inevitavelmente intrincada (LAVE, 2019). Por essa razão, a pesquisa se desenvolveu tanto acompanhando os sujeitos no contexto habitual da prática umbandista (interna e externa ao terreiro) em que são submetidos às etapas dos processos de iniciação e desenvolvimento e onde cumprem suas "obrigações", realizam "trabalhos" e fazem o atendimento a comunidade, quanto em outras situações e circunstâncias do dia a dia dos participantes daquela comunidade.

As atividades de campo revelaram serem elas mesmas um longo aprendizado que em muito ecoaram a expressão "catar folhas", usada por Cossard (1981) para se referir a esse paciente percurso. Ciente da importância de registrar as falas dos sujeitos em diferentes contextos de suas vidas, era fundamental como etnógrafa estar sempre acompanhada dos inseparáveis "instrumentos de trabalho": caderno de campo, lápis e gravador. Entretanto, de livre circulação por todos os cômodos da residência, o gravador era absolutamente proibido no "barracão" (nome dado ao local onde funcionava efetivamente o terreiro de umbanda) ou em ocasiões em que os guias espirituais estivessem manifestados. Assim, buscando realizar uma descrição de toda a dinâmica social do terreiro, progressivamente Bergo (2011) desenvolveu a habilidade muito comum aos etnógrafos de escrever com rapidez e discrição, utilizando estrategicamente códigos, símbolos, abreviaturas e siglas a serem decifradas posteriormente ao longo de muito trabalho a ser realizado distante do campo de pesquisa.

De fato, se em campo as habilidades mais requisitadas ao pesquisador se referem à agilidade e capacidade de registro e síntese, fora dali a transcrição e tradução dessa escrita codificada se mostra uma atividade extremante lenta e minuciosa. Foram, portanto, necessárias muitas horas de trabalho para conseguir realizar a laboriosa tarefa de transformar um amontoando de dados em um texto coerente e inteligível. $\mathrm{Na}$ fase mais intensiva da obser- vação participante, tudo que era visto, ouvido e experimentado em campo ficava ressoando na memória da pesquisadora todo o tempo. A magnitude da experiência vivida naquele contexto a afetava ${ }^{8}$ de tal forma que, ao voltar para a casa, seus pensamentos eram continuamente invadidos por vozes, imagens, trechos de pontos cantados, expressões e gestos característicos de cada uma das entidades do terreiro.

Certamente, o tipo de interação estabelecida com as pessoas do terreiro foi também determinante para o registro satisfatório do vivido e experimentado naquele universo e do que seus interlocutores lhe permitiram aprender. O clima amistoso e alegre predominante ali contribuiu muitíssimo para sua rápida integração ao grupo na condição de pesquisadora. Gentilmente, aqueles filhos de santo foram permitindo que ela se aproximasse e passasse a participar de suas rotinas religiosas.

Um aspecto interessante relativo a isso foi que seu inseparável gravador tornou-se um instrumento facilitador da mediação e aproximação entre os sujeitos. Alvo de muitas brincadeiras e dúvidas sobre a real "utilidade" de tudo que com ele era registrado, foi a presença do gravador que muitas vezes possibilitou a produção de situações interessantíssimas que muito revelaram sobre aquele universo. Conforme registrou em seu caderno de campo, Bergo (2011, p. 28) frequentemente ouviu e gravou frases do tipo:

Acho tão engraçado você pedir pra gravar essas conversas da gente. Uma conversinha normal, assim boba... A gente não tá nem falando nada de mais, aí vem você com o gravador. [Risos].

Tudo você grava, né? Depois eu quero ver o que você vai fazer com esse monte de bobagem que a gente fala.

\section{$[\ldots]$}

Você gravou isso que ele falou? Acho que é importante pra sua pesquisa.

Outro aspecto interessante que marcou a etnografia foi a presença significativa de

8 No sentido que Jeanne Favret-Saada confere à expressão (GOLDMAN, 2005). 
crianças que tomavam parte da prática de umbanda como participantes ativos. Sem que tivesse sido previsto na proposta da pesquisa, o contato direto com as crianças se mostrou uma fonte riquíssima de informações, permitindo que viesse à tona uma série de aspectos extremante relevantes para a compreensão daquela realidade. A maneira como o grupo infantil era tratado pelos adultos e a forma como interagem nas mais variadas atividades da religião evidenciam as concepções nativas de infância e também seus diferentes modos de compreender a aprendizagem (COHN, 2013). A observação participante realizada com os pequenos umbandistas permitiu conhecer a forma como percebiam o processo de iniciação nessa religião, como falavam sobre isso, o que pensavam, o que já sabiam e, principalmente, como sabiam, como tinham acesso às informações e as elaboravam, como praticavam, dentre outros aspectos que estruturavam essa participação na comunidade religiosa. A pesquisa se redefiniu, portanto, buscando compreender a aprendizagem enquanto processo cotidiano de se tornar / de vir a ser / de se produzir umbandista.

Buscando realizar diferentes diálogos teóricos, foi possível compreender, por um lado, as experiências vivenciadas pelos membros do terreiro como percursos de "aprendizagem situada" e o terreiro de umbanda como uma "comunidade de prática" (LAVE; WENGER, 1991); e por outro, os conhecimentos ali (re) produzidos como constituidores da "habilidade" (INGOLD, 2000) umbandista. 0 sentido que Lave e Wenger (1991, p. 32) atribuem ao caráter situado da aprendizagem refere-se "às possibilidades transformadoras de ser e de se tornar um participante pleno no mundo social", definindo a aprendizagem como "produção histórica, transformação e mudança das pessoas" (LAVE; WENGER, 1991, p. 51). A partir de Ingold (2001a, 2001b) concluiu-se que as habilidades constituídas na umbanda nada têm de inatas: são produzidas na e pela prática coletiva constante, pela necessidade de cumprir sua “missão", por pressão da comunidade de prática para que assumam suas funções de tocar os sagrados instrumentos rituais, ou de cuidar do terreiro e dos seus membros, ou ainda de servir como mediador entre os homens e seus deuses e guias espirituais. Longe de ser "natural" ou evidente, todo o gestual e demais aspectos da vivência religiosa supõem aprendizagem, e esta é perene: constante e nunca se esgota.

A aprendizagem da e na umbanda obedece, obviamente, a fundamentos e tradições da religião, porém esse processo não é completamente explícito nem mesmo para os praticantes mais experientes. Isso porque os elementos que o compõem não são universais, muito menos formalmente definidos. De forma similar ao percurso de iniciação do candomblé, também na umbanda "o que se deve aprender não é conceitualizado como um corpo perfeitamente coerente e unificado de regras e conhecimentos, como algum tipo de doutrina sobrecodificada e imposta de cima" (GOLDMAN, 2005, p. 205). 0 conjunto dos saberes é reunido ao longo dos anos até que "adquira uma densidade suficiente para que com ele se possa fazer alguma coisa" (GOLDMAN, 2005, p. 205). Assumindo a perspectiva de que tal processo não é "natural", e não se dá "espontaneamente", foi preciso procurar identificar naquele contexto quem ou o que regula os percursos, explicitando os aspectos invisíveis (na medida em que não eram evidentes) do aprender (na) umbanda.

Na produção final do texto etnográfico, para dar sentido e organização às numerosas e ricas experiências vividas em campo, fez-se a opção analítica de apresentar o material produzido e as reflexões em três categorias que classificavam os aspectos principais identificados ao longo da pesquisa: os modos da participação dos membros no terreiro; os modos das relações entre esses membros; e as ações diretas e indiretas de suporte à aprendizagem por eles produzidas nos espaços e tempos próprios da religião. A participação, as relações e as ações de suporte à aprendizagem foram 
compreendidas no estudo como os "recursos" que estruturavam e organizavam a prática de umbanda, configurados, por fim, como condições determinantes para que a aprendizagem pudesse ocorrer.

Na impossibilidade de tratarmos nos limites do presente artigo de cada um desses três conjuntos de "recursos", para encerrar a apresentação da etnografia aqui focalizada optamos por fazer uma breve referência a um tipo bastante específico de ação que foi classificado sob a categoria nativa de estratégia de aprendizagem (BERGO, 2011). Fizemos essa opção pelo fato de essa categoria analítica permitir compreender aspectos das transformações que ocorriam com os umbandistas, mas também com a própria pesquisadora em seu fazer etnográfico.

0 primeiro aspecto a ser destacado é o fato de que a efetiva identificação da existência de "estratégias de aprendizagem" só foi possível em virtude de uma narrativa feita por um ogã de toque, que chamou atenção da pesquisadora para aspectos da produção de umbandistas aos quais ela ainda não havia dado a devida atenção.

PESQUISADORA: Eu fico impressionada com a quantidade de coisas que vocês têm que saber.

OGÃ: É muita coisa mesmo. [risos].

PESQUISADORA: Como é que vocês conseguem?

OGÃ: A gente tem nossos métodos.

PESQUISADORA: Como assim, métodos?

OGÃ: [risos] Uai, eu por exemplo, eu desenvolvi uma estratégia pra aprender que é assim, é... quando eu não sei as folhas que podem ser usadas na defumação, por exemplo, é só eu ir lembrando do ponto que a gente toca na gira enquanto tá defumando... "com incenso e benjoim, alecrim e alfazema, eu defumo essa casa com as folhas da jurema". [risos]. Entendeu?

PESQUISADORA: Olha só... Entendi... [risos].

\section{$[\ldots]$}

OGÃ: Estratégia, moça. Eu sou um cara esperto [risos]. (BERGO, 2011, p. 195).

90 termo foi utilizado remetendo à noção de "recursos estruturantes" também desenvolvido por Lave e Wenger (1991).
A partir dessa conversa, a pesquisadora, então, vasculhou suas notas de campo, gravações e entrevistas realizadas ao logo de quase dois anos, buscando localizar outras situações em que tal "recurso" esteve presente, mas que na época em que ocorreram ela não era ainda capaz de reconhecer. Empreendendo uma espécie de processo "retroinvestigativo", foi possível localizar no material etnográfico vários registros que remetiam diretamente à noção de estratégia aventada pelo ogã, bem como anotações que faziam referência, direta ou indiretamente, a ideias como exercício, método ou metodologia de aprendizagem. Isso a levou a concluir que era imprescindível se debruçar também sobre a dimensão estratégica da prática umbandista, compreendendo-a como uma componente crucial - juntamente com a participação e as relações - dos principais recursos estruturantes da prática de umbanda.

No processo de releitura de seus dados de campo, foi possível identificar que os membros daquela comunidade de prática possuíam um discurso relativamente elaborado sobre essa questão, em vista do que se podia perceber no início da pesquisa. Contudo, o fato de ter (re) conhecido a dimensão estratégica somente a partir de uma determinada situação de interação com um dos membros evidenciou que, embora recorrentes e potentes, essas ações eram, em certa medida e para alguns, "invisíveis" no sentido de que são absolutamente corriqueiras e dadas como óbvias ou naturais pelos sujeitos envolvidos. Apesar da noção de "estratégia" remeter a intencionalidades, naquele contexto tais ações eram também fluidas e sutis, justamente por serem circunstanciais, inerentes à própria experiência religiosa.

Para que a pesquisadora se atentasse a elas foi preciso uma longa e intensa presença em campo, além de cultivar uma sensibilidade "teoricamente informada" e desenvolvê-la para muito além do uso de procedimentos metodológicos "adequados". Acima de tudo foi necessário que chegasse a ser, ou se deixasse ser, simbólica e misticamente "afetada". 


\section{Engajamento na prática cotidiana: sobre aprendizagens de futebolistas e etnógrafos}

O futebol é um jogo de contato; muito contato entre seres humanos e tem que treinar, porque se você não treinar você não consegue jogar [...] a habilidade você adquire, você já não nasce sabendo não, ninguém nasce sabendo driblar, sempre está acumulando dentro de jogo um drible, um toque mais refinado, sempre você aprimora assim. (FARIA, 2008, p. 171).

A pesquisa de doutorado de Faria (2008) - intitulada A aprendizagem na e da prática social: um estudo etnográfico sobre as práticas de aprendizagem do futebol em um bairro de Belo Horizonte - teve como objetivo descrever como é que se aprende aquilo que pouco se ensina no formato escolar no Brasil: o futebol. 0 pressuposto básico do trabalho é de que o futebol no país se (re)produz a partir de amplos e difusos processos de aprendizagem (nos quais há pouco ensino observável), ou seja, o futebol é prática cultural na qual fica evidente que os processos de aprendizagem são indivisíveis da sua produção cotidiana. Ainda que no Brasil haja situações nas quais o futebol possa estar associado a objetivos educacionais (quando ele é utilizado para disciplinar crianças e jovens), a sua aprendizagem decorre da participação nos diferentes contextos de prática a partir de diferentes formas de engajamento: jogar, assistir, conversar, ensaiar, torcer ou simplesmente "estar lá", são modos de participar que redundam em aprendizagem da e na prática. ${ }^{10}$

Para abordar a aprendizagem do futebol não se colocava como possibilidade, portanto, recortar um contexto de prática (eleito como o lugar da aprendizagem) para realizar a pesquisa de campo. 0 objeto constituído implicou, pois, na escolha de um setting empírico em que os recursos para a aprendizagem do futebol viessem das várias fontes nas quais ele se apresenta.

10 Dentre os estudos que também focalizaram a aprendizagem do futebol, podemos destacar Damo (2005) e Spaggiari (2015).
Respeitando essa característica do futebol no Brasil, a pesquisa de campo realizada em 2005 e 2006 focalizou as práticas futebolísticas de jovens de um bairro da periferia da cidade de Belo Horizonte (MG).

Como professora de educação física, não era tarefa fácil pesquisar aprendizagens fora da escola. Muito pelo contrário, era difícil observá-las fora das práticas pedagógicas e das demarcações escolares que assumem o aprender como o resultado de relações de ensino, de transmissão e internalização. Como argumenta Lave (2011), há um mito sobre o aprender que, historicamente, reduziu as descrições da aprendizagem ao âmbito da escola. A hegemônica compreensão da escola como o lugar social da aprendizagem e a centralidade da escolarização no nosso contexto sócio-histórico (com a assimetria da relação mestre/aprendiz) incide, entretanto, para além do âmbito da educação escolar. Ela impacta as relações cotidianas, uma vez que produz apagamento das práticas culturais forjadas fora do parâmetro da forma escolar e cria opacidade para as outras relações cotidianas de aprendizagem. Assim, quando se é provocado a narrar sobre o modo como práticas culturais se constituem e constituem sujeitos, pouco (ou nada) se consegue observar/ descrever. Esse foi um dos desafios enfrentado por Faria (2008) no decorrer da pesquisa sobre a aprendizagem do futebol. Como observar e descrever práticas de aprendizagem quando não há ninguém ensinando? No percurso da pesquisa do futebol, a pesquisadora precisou constituir (aprender) maneiras para acessar as práticas de aprendizagem do futebol - práticas as quais já de início sinalizavam não se circunscrever e, até mesmo, questionar a lógica da noção de transmissão.

A singularidade da etnografia é que, embora ela se produza das relações entre o etnógrafo e muitos mestres - como afirma Velho (2006), mestres acadêmicos e mestres do campo -, não há contextos e processos de ensino desse ofício. 0 etnógrafo não existe a priori. Ele se constitui no mosaico das complexas relações 
entre pares e no aprendizado que emerge do entrelaçamento das relações cotidianas com os diferentes mestres.

A abordagem situada da aprendizagem de Lave e Wenger (1991) e as relações da aprendizagem com a vida cotidiana que Lave (1982, 2011) vinha desenvolvendo desde o seu trabalho sobre os alfaiates da Libéria tornaram-se uma referência central na pesquisa sobre o futebol. 0 fato é que no cotidiano da pesquisa o conceito de participação periférica legitimada de Lave e Wenger (1991) permitiu desvelar aspectos das práticas futebolísticas obscurecidos pela hegemonia das relações de ensino. Tornou-se, portanto, uma lente a partir da qual se poderia desdobrar possibilidades de observar aprendizados acontecendo no curso da prática cotidiana.

A aprendizagem como "atividade situada" constitui a definição central do processo que Lave e Wenger (1991, p. 29) chamam de participação periférica legitimada (PPL), ou seja, processo pelo qual aprendizes participam em comunidades de prática em que o domínio do conhecimento e das habilidades requer movimento em direção à "participação plena nas práticas socioculturais". A aprendizagem "como um aspecto inseparável e integral da prática social" é o que propõem os autores, sob a rubrica PPL (LAVE; WENGER, 1991, p. 29). Oferecendo uma forma de falar sobre as relações entre os novatos e veteranos e sobre atividades, identidades, artefatos e comunidades de conhecimento e prática, a PPL é um "ponto de vista analítico sobre a aprendizagem" (LAVE; WENGER, 1991, p. 29), em que "saber/ conhecer e aprendizagem são parte da prática social" (LAVE; WENGER, 1991, p. 40). Portanto, é "proposta como um descritor do engajamento na prática social que acarreta aprendizagem" (LAVE; WENGER, 1991, p. 34-35).

Apontando os limites das "explicações convencionais" (que percebem a "aprendizagem como um processo pelo qual o aprendiz internaliza o conhecimento já descoberto, transmitido por outros"), Lave e Wenger (1991, p. 33) sugerem que: "a aprendizagem é um processo que toma lugar em uma estrutura de participação, não em uma mente individual”. Isso implica "ênfase no entendimento compreensivo envolvendo a pessoa por inteiro" (e não o recebimento de um corpo de conhecimento sobre o mundo). Além disso, implica na visão de que agente, atividade e mundo se constituem mutuamente, ou seja, o sujeito se constitui no mundo ao mesmo tempo em que constitui o mundo (processo circular).

0 estudo do futebol feito a partir dessa lente permitiu desvelar aprendizagens onde antes nada se via. Uma aprendizagem invisível que, muitas vezes, é confundida, ou afirmada como dom. Permitiu também compreender a necessidade de configurar o campo de pesquisa respeitando os espaços de participação dos jovens no futebol: a) nas aulas de Educação Física; b) no recreio na escola; c) no campo de futebol do bairro (nas práticas de futebol do projeto social, nos treinos do time juvenil e infantil, nos jogos amistosos e de campeonatos, nas práticas de lazer); d) na Praça de Esportes; e) em outros campos de futebol da cidade (campeonato amador).

A escolha e o acesso ao contexto da pesquisa de campo são completamente definidos pelas relações em campo. Trata-se de processo de negociação, na qual as partes vão se afinando e aprendendo a estabelecer limites e possibilidades. 0 início da pesquisa de campo (que começa antes da formalização da pesquisa) inaugura, portanto, a participação do pesquisador nas práticas investigadas e torna-se, desse modo, a possibilidade de acesso ao sistema de relações da qual, a partir daí, ele também passa a fazer parte.

A pesquisa do futebol exigiu negociações e formalizações explícitas. No entanto, a autorização para a pesquisa não garante o acesso d̀ prática. Como afirmam Lave e Wenger (1991), o acesso está diretamente relacionado à possibilidade de ser um praticante legítimo da prática em questão. Nesse sentido, é preciso destacar que, embora o futebol no Brasil seja uma práti- 
ca pública e difusa no cotidiano, ela é também generificada. Assim, os praticantes legítimos (que alcançam possibilidades de participação e, consequentemente, aprendem) são em sua maioria homens. ${ }^{11}$

Ser uma pesquisadora/mulher no âmbito do futebol é produzir um movimento de mergulho numa prática masculina e ultrapassar limites silenciosos, mas socialmente pactuados. Constituir (aprender) maneiras de aproximação e, ao mesmo tempo, lidar com as possibilidades de acesso permitidas pelos membros é um dos desafios enfrentados por uma pesquisadora/mulher nesses contextos - o que geram questões do tipo: Em que termos ocorreria a observação? Qual o tipo de inserção no futebol é possível a uma mulher? Tal como os jovens praticantes do futebol, a pesquisadora precisou aprender sobre o seu modo de participação possível; sobre o que a inserção possibilitada poderia efetivamente permitir e limitar.

Iniciei a pesquisa de campo do futebol no bairro após autorização dos professores e treinadores que orientavam as práticas juvenis. A participação feminina, nos contextos de produção do futebol do bairro, no entanto, muitas vezes destoava da lógica do lugar. Na maior parte das vezes em que fui ao campo, era a única mulher presente. A evidente exclusão das mulheres dessa prática reapresentava a forte demarcação de gênero nesse esporte. Desse modo, as questões de gênero atravessaram toda a produção de dados. (FARIA, 2008, p. 46).

Conversar sobre a aprendizagem do futebol com os participantes da pesquisa sempre gerava debate sobre um fenômeno que, de tão familiar (naturalizado), é também desconhecido. Nas relações com os meninos, jovens e homens (com o masculino) eu me sentia marcada pela diferença. Conversar com esses participantes sobre a pesquisa me deslocava de posição. Passava do lugar de quem sabe (pois anunciar uma pesquisa de doutorado me dava certo status) para o lugar de quem não sabe, enquanto o inverso acontecia com os meus informantes. Então jogadores de futebol na escola, boleiros de fim de tarde no campo do bairro, 'atletas' de fim de semana, professores e treinadores etc., passavam a me conduzir - como se conduz um iniciante - no tema de

11 Ainda que o gênero seja um tema de amplo debate nos estudos sobre futebol no Brasil, ainda são escassos os trabalhos sobre a participação das mulheres nesse campo. pesquisa. (FARIA, 2008, p. 44, grifo nosso).

As práticas de futebol no campo de futebol eram marcadas por linguagens, gestos e conversas sobre futebol que pareciam (na visão dos participantes) extremamente adequadas ao espaço masculino. A questão da linguagem não passou despercebida, entretanto, pelo treinador que, durante os primeiros treinos observados, fazia recomendações explícitas sobre a minha presença (feminina) e a proibição do uso de palavrões. Mas o tempo extenso de pesquisa de campo foi dando lugar a certa naturalização da minha presença. Portanto, fomos construindo um tipo de relação em que cada um podia se comunicar sem ter que se transformar no outro: nem eu passei a falar como eles (mesmo porque isso não era esperado de uma mulher), nem os jovens se constrangiam em falar na minha presença. (FARIA, 2008, p. 47).

A pesquisa de campo talvez permita ao etnógrafo uma noção justa das implicações da afirmação de Lave (2011, p. 133-134): "somos todos aprendizes de nossa própria prática em mudança". Afinal, embora a pesquisa de campo faça parte de um processo de planejamento estruturado e na qual o pesquisador já tenha investido esforços na compreensão do objeto, a imersão no campo supera as expectativas e os desafios descritos nas análises teóricas. 0 campo (a participação) constitui, portanto, contexto central de aprendizagem da observação participante que o pesquisador se propõe a fazer. Conforme os futebolistas envolvidos com o futebol, também o etnógrafo precisa lidar com o paradoxo de que é necessário aprender para fazer; e fazer para aprender (FARIA, 2008).

No cotidiano da pesquisa, Faria (2008) teve que se haver com vários dilemas e questões. A pergunta básica - por onde começar? - rapidamente se mostra apenas como a ponta do iceberg. Muitas outras perguntas e tomadas de decisão vão sendo constituídas e constitui o pesquisador no processo de imersão no campo: Como abordar e conversar com as pessoas? Como se vestir e o que levar para o campo? Como fazer os registros das práticas? Como se posicionar no campo? Interferir diretamente ou observar (por exemplo, ao presenciar uma briga entre os jovens)?, dentre outras questões que configuram o ofício. 
Nas práticas de futebol dos jovens do bairro evidenciavam-se ditos e não-ditos, numa linguagem pautada no silêncio e na fala e, de qualquer forma, incrustada no corpo. Eu tentava compreender o que diziam aqueles corpos juvenis. Precisava elaborar, portanto, estratégias para alcançar os modos de organização da prática (da qual a aprendizagem era parte). Contudo, como aqueles jovens, eu estava passando por um processo de aprendizagem. No decorrer da pesquisa é que fui constituindo uma percepção ampliada da dinâmica do futebol e dos seus modos de aprendizagem. Fui constituindo na prática a habilidade de pesquisadora (INGOLD, 2001b). Assim, aos poucos (e num exercício prático) comecei observar aprendizagens onde antes não via. Mergulhei nesse exercício. Outra estratégia utilizada foi o uso dos contrastes nas práticas futebolísticas: diferenças entre os futebóis femininos e masculinos; diferenças na aprendizagem do futebol e de outros esportes; diferenças dos contextos de produção do jogo no bairro; etc. (FARIA, 2008, p. 46).

Aprender as rotinas, horários e fluxos de pessoas; aprender a ser visível/participante (já que é impossível ser invisível); aprender a lidar com as expectativas dos pesquisados (como nos casos de jovens e mães que viam na pesquisadora possibilidades de ascensão no futebol); aprender a se comportar em campo (compreender os códigos colocados à sua presença); aprender a falar "caralho" como exclamativa convincente; aprender a suportar o trabalho exaustivo de ficar horas tentando compreender o que ali acontece (mesmo quando tudo parece repetitivo); aprender a lidar com o imponderável; são apenas alguns dos aspectos com os quais a pesquisadora teve que lidar.

A prática de pesquisa de campo trata-se, também, de um processo de educação da atenção (INGOLD, 2001b) que inclui a aprendizagem da própria presença:

Na escola, foi difícil escapar da demarcação de papéis da instituição. A entrada de um adulto no contexto posiciona-o imediatamente: professor, futuro professor, estagiário, pai de aluno, membro da direção. Para minimizar o impacto da minha presença, procurei escapar dessas classificações, ficando sempre onde estavam os alunos. Desse modo, sentava na arquibancada com eles no decorrer das aulas de Educação Física, assistia aos jogos do campeonato do lado em que eles ficavam na quadra e buscava me aproximar dos grupos de conversa. Percebi, então, que uma relação de confiança foi sendo tecida: nas conversas sobre o desempenho de alguns jogadores na escola (e fora dela); nas 'tarefas' de tomar conta do material de alguns alunos na quadra (muitos ficavam preocupados com roubos); na leitura dos cadernos dos alunos decorados com escudos e figurinhas dos times profissionais; nas conversas sobre outros assuntos. (FARIA, 2008, p. 44, grifo do autor).

Engana-se quem acredita que o etnógrafo tem o controle das situações e de que ele é quem dirige o empreendimento da pesquisa de campo. É apenas à medida que ele consegue perceber que pode agir (INGOLD, 2001b). 0 trecho que segue pode ser tomado com uma cena emblemática da complexidade de tais processos.

Conheci Biruga (no seu ofício de descobrir jovens para compor os times do Racing) em meados de 2005 nas imediações da escola. Com motivações distintas e papel e caneta nas mãos, ele e eu observávamos o mesmo jogo de futebol de um grupo de jovens, em uma aula de Educação Física. Acompanhando uma aula que acontecia na Praça de Esportes em frente à escola, já que a quadra da escola estava ocupada com outras atividades, comecei a notar a presença e as intervenções de um homem, no jogo de futebol dos alunos. Sentado em um degrau próximo à quadra, chamando muitos jovens pelo nome e perguntando os nomes daqueles que não conhecia, ele zombava/brincava com os que já conhecia, convocava para o treino do time Juvenil, jovens que estavam participando da aula ('- Quarta-feira às quatro horas.') e também para o amistoso do final de semana ('- Sábado se ganhar tem lanche'). Observando o jogo, Biruga também convidava outros jovens, que se sobressaiam no futebol, para participar do treino dos times do Racing. Após a aula, enquanto conversava com alguns jovens, fui informada de que Biruga era treinador do Racing e estava recrutando jovens para os treinos de futebol do time infantil/juvenil e, consequentemente, da Copa de Juvenil de Futebol Amador da cidade. 
Nesse mesmo dia, no trajeto da escola para casa, encontrei Biruga em frente à banca de revista nas imediações do campo de futebol. Apresentei-me e falei do interesse em acompanhar os treinos e os jogos do Racing no campeonato. Biruga consentiu prontamente a observação das práticas. (FARIA, 2008, p. 137).

A pesquisa de campo desfaz, em muitos sentidos, a noção amplamente enraizada na sociedade de que os mais novos aprendem com os mais velhos. No caso da pesquisa do futebol isso se apresenta de pelo menos duas maneiras: primeiro, porque a sua aprendizagem subverte essa lógica e o mais habilidoso nem sempre é o mais velho; segundo, porque o pesquisador se torna também aprendiz das práticas pesquisadas, ou seja, o campo o reposiciona, sendo ele quem aprende: seja com os adultos, com os jovens, os idosos ou as crianças. "Levar a sério o que dizem os nativos" (VIVEIROS DE CASTRO, 2002) e produzir simetria entre os conhecimentos nativos e os do pesquisador (GOLDMAN, 2006) é o que garante que tais aprendizagens possam ocorrer. Aqui vale a pena reportar o aprendizado com um jovem pesquisado de 16 anos. A lucidez com a qual ele define o futebol na epígrafe "O futebol é um jogo de contato; muito contato entre seres humanos" (FARIA, 2008, p. 90) talvez possa ser tomada como um modo de descrever as múltiplas situações de aprendizagem da etnografia.

É importante retomar aqui, entretanto, uma característica marcante do futebol: os mecanismos velados de exclusão. Assim, no bairro pesquisado, aos jovens que tinham dificuldade de progredir/aprender, a participação não era negada abertamente. Ficavam "gelados" até que resolvessem abandonar o jogo - o que acabava por marcar os jovens, visto que, mais do que o manejo da bola, o que estava em questão eram as identidades dos aprendizes. Para suportar tal processo (e permanecer no futebol) era preciso desenvolver outras disposições. Conforme explicou Pelé (jovem de 12 anos), o importante no futebol é não perder a calma: “Tem gente que já fica nervoso, já não quer jogar mais. Mas ninguém vai aprender sem jogar futebol não. Você não pode ficar nervoso. Você tem que ter calma." (FARIA, 2008, p. 127).

No processo de pesquisa, Faria (2008) esteve atenta ao fato de que também as suas possibilidades de acesso à prática estavam relacionadas à permanência em campo e às mudanças na sua forma de participação. Tal como os futebolistas, havia o risco de que ela fosse excluída do jogo - o que impediria seus deslocamentos entre as práticas.

A pesquisa de campo se constitui, então, em um processo de transformação do pesquisador. Todavia, o relato etnográfico não surge de forma automática ao final do percurso. Ele exige muitos outros esforços de aprendizagem, também, na prática da escrita. Assim, não basta (re)produzir os relatos, traçando, passo a passo, as etapas da pesquisa, as decisões tomadas no campo e as implicações nos dados produzidos. Se tais informações são fundamentais à leitura de qualquer pesquisa, elas deixam escapar o processo vivido. Afinal, como falar de uma trajetória de pesquisa sem falar da trajetória da pesquisadora? Como explicar o mergulho no contexto observado sem tratar das emoções vividas no decorrer da investigação? Como falar de práticas corporais (da habilidade futebolística) sem tratar do lugar ocupado pelo próprio corpo? Muitas foram as questões produzidas no estudo do futebol e anunciá-las ajuda a elucidar o grau de envolvimento e ajuda a entrelaçar a produção da pesquisa com a da pesquisadora.

Após mais de um ano de imersão e a produção de páginas e páginas de notas de campo e de entrevistas, era impossível para FARIA (2008) escapar à pergunta: Como dar legibilidade aos dados, à experiência do campo? Afinal, o mundo não se organiza em categorias explicativas. Os dados acumulados não produzem automaticamente um entendimento organizado em termos de temas e capítulos. Nós é que tentamos transformar a complexidade da vida cotidiana em uma estrutura linear (ATKINSON, 1992). Atenta a essa complexidade, FARIA 
(2008) foi tentando compor a aprendizagem do futebol com os seus múltiplos aspectos.

Para desvelar os modos de aprender, a pesquisadora colocou foco no futebol procurando analisar como os jovens iniciantes se tornavam veteranos. Esse engajamento no futebol do bairro lhe dava, contudo, a mesma impressão da onda observada pelo personagem Palomar, de Ítalo Calvino (1994): sem início nítido, sem fim delimitado. Por onde começar? Como focar as aprendizagens dos jovens (heterogêneos) e, ao mesmo tempo, considerar outros interlocutores nesse processo dinâmico e multifacetado? No bairro pesquisado o futebol era produzido nas relações entre crianças, jovens e adultos, em contextos diferenciados. Buscando desvelar o que seria a aprendizagem, Faria (2008) concentrou esforços de descrição dos modos de participação dos jovens na prática a partir do conceito de participação periférica legitimada (LAVE; WENGER, 1991). Com isso, tentou focar os recursos de aprendizagem da prática, tentando superar a noção de aprendiz individual e descentralizar a análise da figura do mestre (pedagogo) e do ensino.

A participação nos contextos de futebol do bairro (posição na qual obteve legitimidade) permitiu que a pesquisadora pudesse bordejar aspectos importantes da aprendizagem dessa prática social, sem nela se tornar uma jogadora futebol. Portanto, o trabalho foi feito por alguém que, após ter vivido a experiência de pesquisa de campo, pôde mostrar aspectos que a imersão total no jogo pode esconder ou não deixa ver com clareza (DAMATTA, 2006).

De outro modo, a releitura das práticas de pesquisa realizadas permitiu à pesquisadora compreender que, tal qual os praticantes do futebol, a aprendizagem da etnografia também se dá na prática. Pode-se dizer que exercício de aprendizagem dos jovens no futebol e o da pesquisadora são da mesma ordem: trata-se de um processo de participação no qual a permanência em campo é fundamental.

Dentre os aprendizados no âmbito do futebol (com os futebolistas), Faria (2008) sin- tetiza: a) que o aprender não é sinônimo do ensinar, mas sim do viver! Aprende-se sempre; b) que o aprender se dá na relação entre pares: entre sujeitos de diferentes idades e diferentes domínios da prática; c) que o aprendizado envolve muitos aspectos para além do jogo em si trata-se de exercício de constituição da pessoa e da prática; d) que o aprender é resultado da participação na prática social; e) que o acesso (que envolve a legitimidade de participação de alguns e não de outros) e a permanência na prática são fundantes no processo de aprender. Entretanto, também que a exclusão é eminente: assim, nem todo mundo aprende.

0 etnógrafo não sai imune da prática etnográfica. De fato, o processo de imersão da pesquisa é uma experiência singular para o pesquisador - que no caso de Faria (2008) saiu marcada na forma de compreender as práticas de futebol e as relações (de aprendizagem) que envolvem a produção desse esporte na sociedade, mas também a forma de ver a si mesma - marcas que se projetam no corpo, no agir/sentir.

\section{Considerações para continuar a}

\section{conversa}

Lave (2019) afirma que uma leitura muito comum do livro Situated Learning simplesmente retorna a divisões dualistas antigas, mesmo se se admite algo novo - a ideia de aprendizagem situada -, mas depois reafirmando que esse seria apenas o outro polo em relação a formas gerais, não situadas, frequentemente "modernas" ou "avançadas" de aprendizado. "Mas o argumento de Situated Learning foi enfático. Toda aprendizagem é situada. Não há exceções" (LAVE, 2019, p. 139).

Essas orientações (apenas parcialmente apresentadas antes) nos serviram para desenvolver exercícios etnográficos em diferentes contextos, como os dois aqui apresentados, e ainda temas como as práticas tradicionais entre os povos indígenas (SILVA, 2011), tarefas da vida cotidiana em contextos urbanos (DRUM- 
MOND, 2014), dentre outras que podiam em alguma medida ser incentivadores e instigadores na forma de interagir com a investigação uns dos outros (GOMES; FARIA, 2015).

Nesse sentido, elas solicitam antes de mais nada que o etnógrafo esteja em permanente reflexão sobre a sua forma de participação, buscando explicitar suas premissas (BATESON, 1972) e confrontá-las com as premissas dos demais com quem ele interage.

Essa reflexão não é nova na prática da etnografia - de fato não o é! A diferença aqui seria, talvez, introduzir o tema da aprendizagem como um tema caro - diríamos até mais, um tema estratégico - na interface entre investigações dos campos da antropologia e da educação. Um tema que, nessa perspectiva, deve entrar de forma simétrica e provocar uma contínua revisão de premissas e posições, especialmente por parte dos pesquisadores em razão de sermos todos provenientes de contextos escolarizados (a universidade é um deles). Ou seja, é um tema estratégico, mas que nos põe a prova; e no qual é grande nosso risco de reproduzir preconcepções, que vão desde o que pode ser assumido como a natureza da pessoa humana (SAHLINS, 2008), do que podem ser as relações que constituem essas pessoas, até a ideia mesma do que seja aprender.

Contudo, como Lave (2019) nos propõe: introduzir o tema da aprendizagem significa descentrar do tema da aprendizagem. Esse é o exercício que estamos progressivamente produzindo.

Em outras palavras, uma etnografia sensível às questões que envolvem o que chamamos de aprendizagem deve ser uma etnografia que poderia até iniciar por se abster do uso desse termo, como a própria Lave nos sugeriu em uma de suas palestras na UFMG em 2011. Não se trata, portanto, para o que estamos nos propondo, de desenvolver um campo específico de investigação - algo como uma antropologia da aprendizagem, ou estudos educacionais da aprendizagem -, mas desenvolver uma prática de investigação que leve em conta o que acontece - e sempre acontece - em termos de aprendizagem nas práticas em curso (alguns podem chamar de reprodução da prática; outros de formação da pessoa). ${ }^{12}$

Essa postura é semelhante, em certos aspectos, ao que propõe Christina Toren (1999) quando nos fala da importância de envolver as crianças nas investigações das práticas ou convenções de uma dada cultura, ou mais precisamente, como formula a própria Toren (1999), quanto às formas de socialidade que caracterizam uma dada comunidade ou povo. Segundo Toren (1999), sem essa perspectiva, muito do que precisamos conhecer sobre essas formas de socialidade não emerge, não se revela.

Essa atenção com a específica configuração das práticas de modo a revelar o que Lave (2019) refere como "condições de possibilidade da aprendizagem" pode ser parte integrante de qualquer investigação, ainda que ela não seja voltada especificamente para o tema da aprendizagem. Essa primeira postulação programática busca, assim, promover um campo amplo de observação e de registro etnográfico, que pode permitir, como temos tentado fazer, o diálogo entre pesquisadores de diferentes âmbitos e envolvidos com diferentes temáticas.

Se, por um lado, tal proposição abre um campo de comum interesse para pesquisadores, é muitíssimo presente a demanda em diferentes comunidades (usamos aqui o termo quase como uma provocação) de permitir ou promover a continuidade de suas práticas - de toda ordem: práticas de produção de música, de produção de artefatos, rituais, de subsistência, práticas de cuidado e de cura etc.

Aqui pensamos que as duas categorias que emergem na revisão que faz Lave (2019) - acesso e participação - podem ser boas referências que nos guiam nesse panorama mais amplo. Muitos dos processos da chamada globalização, ou mesmo da "modernização" - ou introdução de padrões da modernidade em configurações sociais consideradas não modernas - promo-

12 Para Bateson (1972), a modificação ou autorregulação de um organismo através da integração de informação sobre ele próprio é o que poderia ser chamado de aprendizagem. 
vem exatamente essa mudança no acesso e nas formas de participação nas práticas. Assim como promovem a introdução de novas práticas e outras formas de participação. Muito frequentemente vemos uma leitura surpresa dos próprios praticantes quanto às dificuldades de se "manter a tradição", ou mesmo de se viabilizar o exercício de uma determinada prática, pois essa percepção vem quase sempre a reboque de outras considerações que introduzem essas modificações (a escola como uma entre muitas das modificações introduzidas). Uma leitura mais atenta, que evidencie de forma mais incisiva essa dimensão implícita das práticas - a de gerar as condições de possibilidade de sua aprendizagem -, poderia interessar a muitos de nós, pesquisadores e pesquisadoras, assim como aos próprios praticantes, em relação àquilo que percebemos como algo que nos é caro e de grande valor.

No caso da umbanda, o processo de aprender é caracterizado pelo que Goldman (2005) observou - reportando à experiência que Cossard (1981) descreveu como "catar folhas" - ou seja, uma paciente participação na vida diária do terreiro, ao mesmo tempo que um compromisso com os momentos rituais, colhendo as ocasiões para progressivamente ir tornando-se um umbandista mais qualificado e experiente. Um processo que não tem fim, no qual todos se percebem na condição de aprendiz em diferentes estágios.

Dessa mesma forma, o processo de aprendizagem da etnógrafa no terreiro de umbanda teve que assumir esse modo de inserção na prática: conseguir fazer parte ativa da condução cotidiana e se surpreender pelo fluxo contínuo de questões e informações que passou a perceber. Daí a necessidade de desenvolver suas habilidades de registro dentro desse fluxo denso e ininterrupto - entre encontros rituais e cotidianidade - que caracterizava a vida no terreiro. As pequenas ações contínuas e cotidianas de suporte à aprendizagem (os recursos estruturantes) davam lugar a esse "catar folhas", porém com estratégias intencionais pelas quais os praticantes se guiavam. Cada momento cotidiano como o recolher de algo que compunha um fluxo progressivo e distribuído, diluído no tempo, de se progredir dentro da prática, conduzido em interações várias entre os vários agentes, atores e entidades.

No caso do futebol, indagado nesse contexto de sua muito inicial configuração (não se trata das práticas que envolvem profissionais), em lugar de se encontrar como centro da prática a imagem mais habitual de um jogador com sua habilidade individual de lidar com a bola, descobriu-se, através dos praticantes, a centralidade de um processo relacional, em que a atenção era voltada para as pessoas e o modo como elas se deslocavam em campo. Ao mesmo tempo, esses deslocamentos eram continuamente tensionados pelo risco de ser excluído do jogo, caso essa mesma habilidade não fosse constituída.

Da mesma forma, a aprendizagem da etnógrafa foi marcada por essa dinâmica de atenção nas relações e do sempre possível horizonte de "exclusão do jogo", metaforizando algo para além do futebol, algo que faz pensar na sociedade brasileira como um todo, com o exercício perene, até hoje não resolvido, de lutar contra a exclusão.

Fazer um cotejamento entre os dois cenários de pesquisa e de imersão das etnógrafas pode ser, portanto, muito revelador. Em um caso, uma prática como a do futebol, que é caracterizada pela contínua e ampla exposição social, que é dada a ver em diferentes contextos e difundida por diferentes canais. No outro, uma prática religiosa que ocorre em locais reservados, de forma circunscrita e codificada. Em ambos os casos, buscar apreender os processos de aprendizagem significou uma imersão na cotidianidade e uma navegação atenta pelas específicas configurações da prática.

Com esses dois casos, buscamos trazer à luz os sentidos da proposta conceitual-metodológica de assumir que aprender é, portanto, modificar a própria participação na prática, ela mesma em mudança - e nesse sentido a própria 
prática etnográfica é emblemática do processo de aprender. Para colher melhor esse processo relacional e contínuo, é preciso voltar nossa atenção, antes de mais nada, para a configuração da prática em questão, e das relações entre os praticantes, e nelas buscar aferir, de forma sempre situada, as condições de possibilidade da aprendizagem.

\section{REFERÊNCIAS}

ATKINSON, P. Understanding ethnographic texts. London: Sage Publications, 1992.

BATESON, G. Steps to an ecology of mind. Chicago: University of Chicago Press, 1972.

BERGO, R. S. Quando o santo chama: o terreiro de umbanda como contexto de aprendizagem na prática. 2011. 249 f. Tese (Doutorado de Educação) - Faculdade de Educação da Universidade Federal de Minas Gerais (UFMG), Belo Horizonte, 2011.

CALVINO, I. Palomar. Tradução de Ivo Barbosa. São Paulo: Companhia da Letras, 1994.

CAPUTO, Stela Guedes. Educação em terreiros - e como a escola se relaciona com crianças de candomblé. Rio de Janeiro: Pallas, 2012.

COHN, C. Concepções de infância e infâncias: um estado da arte da antropologia da criança no Brasil. Civitas, Porto Alegre, v. 13, n. 2, p. 221-244, 2013. COSSARD, Gisèle Binon. "A Filha de Santo". In: MOURA, C. E. M. (org.). Olóòrisà: escritos sobre a religião dos Orixás. São Paulo: Agora, 1981. p. 133-156.

DAMATTA, R. O ofício de etnólogo, ou como ter Anthropological Blues. In: NUNES, E. A Aventura sociológica. Rio de Janeiro: Zahar, 1978. p. 23-35.

DAMATTA, R. A bola corre mais que os homens. Rio de Janeiro: Rocco, 2006.

DAMO, A. S. Do dom à profissionalização: uma etnografia do futebol de espetáculo a partir da formação de jogadores no Brasil e na França. 2005. $435 \mathrm{f}$. Tese (Doutorado em Antropologia) - Instituto de Filosofia e Ciências Humanas da Universidade Federal do Rio Grande do Sul (UFRGS), Porto Alegre, 2005.

DRUMMOND, A. F. Participação de crianças e de adolescentes nas tarefas domésticas. 2014. 125 f. Tese (Doutorado em Ciências da Reabilitação) -
Escola de Educação Física, Fisioterapia e Terapia Ocupacional da Universidade Federal de Minas Gerais (UFMG), Belo Horizonte, 2014.

FARIA, E. L. A aprendizagem na e da prática social: um estudo etnográfico sobre as práticas de aprendizagem do futebol em um bairro de Belo Horizonte. 2008. 229 f. Tese (Doutorado) Faculdade de Educação da Universidade Federal de Minas Gerais (UFMG), Belo Horizonte, 2008.

GOLDMAN, M. Formas do saber e modos do ser: observações sobre multiplicidade e ontologia no Candomblé. Religião e Sociedade, Rio de Janeiro, v. 25, n. 2, p. 102-120, 2005.

GOLDMAN, M. Alteridade e experiência: antropologia e teoria etnográfica. Etnográfica, Lisboa, v. 10, n. 1, p. 161-173, maio 2006.

GOMES, A. M. R. Um (possível) campo de pesquisa: aprender a cultura. In: TOSTA, S. P.; ROCHA, G. (org.). Diálogos sem fronteira: história, etnografia e educação em culturas ibero-americanas. Belo Horizonte: Autêntica, 2014. p. 205-220.

GOMES, A. M. R.; FARIA, E. Etnografia e aprendizagem na prática: explorando caminhos a partir do futebol no Brasil. Educação e Pesquisa, São Paulo, v. 41, n. especial, p. 1213-1228, dez. 2015.

GOMES, A. M. R. et al. Learning [the] culture in Brazil among soccer players and traditional groups. In: AAA ANNUAL MEETING, 111., 2012, San Francisco. Annals [...]. San Francisco, 2012.

INGOLD, T. The perception of the environment: essays on livelihood, dwelling and skill. New York: Routledge, 2000.

INGOLD, T. The debated mind: evolutionary psychology versus ethnography. Oxford: Harvey Whitehouse, 2001a.

INGOLD, T. Beyond art and technology: the anthropology of skill. In: SCHIFFER, M. B. Anthropological perspectives on technology. Albuquerque: University of New Mexico Press, 2001b. p. 17-31.

LAVE, J. A comparative approach to educational forms of learning processes. Antropology \& Education Quarterly, v. 13, n. 2, p. 181-188, 1982. Special issue.

LAVE, J. Apprenticeship in critical ethnographic practice. Chicago: University of Chicago Press, 2011. 
LAVE, J. Learning and everyday life. Cambridge: Cambridge University Press, 2019.

LAVE, J.; WENGER, E. Situated learning: legitimate peripheral participation. Cambridge: Cambridge University Press, 1991.

OLIVEIRA, A.; ALMIRANTE, K. A. Criança, terreiro e aprendizagem: um olhar sobre a infância no candomblé. Estudos de Religião, v. 31, n. 3, p. 273297, set./dez. 2017.

RABELO, Miriam Cristina. Aprender a ver no Candomblé. Horizontes Antropológicos, v. 21, n. 44, p. 229-251, 2015.

RABELO, Miriam Cristina; SANTOS, Rita Maria Brito. Notas sobre o aprendizado no Candomblé. Revista FAEEBA, v. 20, n. 35, p. 187-200, 2011.

SAHLINS, M. The western illusion of human nature. Chicago: Prickly Paradigm Press, 2008.

SILVA, R. C. Circulando com os meninos: infância, participação e aprendizagens de meninos indígenas Xakriabá. 2011. 230 f. Tese (Doutorado em Educação) - Faculdade de Educação da Universidade Federal de Minas Gerais (UFMG), Belo Horizonte, 2011.

SPAGGIARI, E. Família joga bola: constituição de jovens futebolistas na várzea paulistana. 2015.470 f. Tese (Doutorado em Antropologia) - Faculdade de Filosofia, Letras e Ciências Humanas da Universidade de São Paulo (USP), São Paulo, 2015.

STRATHERN, M.; TOREN, C. The concept of society is theoretically obsolete. In: INGOLD, T. (org.). Key debates in anthropology. London: Routledge, 1996. p. 57-96.

TOREN, Christina. Mind, materiality and history: explorations in Fijian ethnography. London: Routledge, 1999.

VELHO, O. Trabalhos de campo: antinomias e estradas de ferro. Aula inaugural no Instituto de Filosofia e Ciências Humanas da Universidade do Estado do Rio de Janeiro. Rio de Janeiro: UERJ, 2006. VIVEIROS DE CASTRO, E. 0 nativo relativo. Mana, Rio de Janeiro, v. 8, n. 1, p. 113-148, 2002.

WACQUANT, Loic. Corpo e alma: notas etnográficas de um aprendiz de boxe. Tradução Ângela Ramalho. Rio de Janeiro: Relume Dumará, 2002.

Recebido em: 15/08/2019 Aprovado em: 30/11/2019 